\title{
NA CONTRAMÃO DA DEMOCRACIA: a crescente indicação política de gestores escolares em Alagoas
}

\author{
Isabela Macena dos Santos' \\ Eva Pauliana da Silva Gomes² \\ Edna Cristina do Prado3
}

\begin{abstract}
RESUMO
Este artigo apresenta um mapeamento das formas de escolha do gestor escolar na rede pública municipal de ensino de Alagoas, ao mesmo tempo que analisa as percepções dos secretários de educação sobre o perfil do gestor escolar, eleição e indicação de diretores. O estudo foi realizado por meio de uma pesquisa quantitativa com aplicação de questionário com os secretários de educação e presidentes do Sindicato dos Trabalhadores da Educação em Alagoas (SINTEAL), com objetivo de compreender as formas de provimento do cargo de gestor escolar da rede municipal de ensino alagoana. A análise dos dados foi feita a partir da Análise de Conteúdo (BARDIN, 2011). Os resultados apontam que Alagoas vem fazendo um caminho contrário ao que determina a meta 19 do Plano Nacional de Educação - PNE (2014-2024), no que tange à utilização de formas mais democráticas de escolha do gestor escolar, pois, ao fazer a comparação com pesquisa realizada em 2013 sobre as formas de escolha do gestor escolar, constatou-se que, após sete anos, ainda a indicação política é a forma de provimento predominante na rede municipal do estado.
\end{abstract}

Palavras-chave: Indicação Política. Plano Nacional de Educação. Alagoas.

\section{AGAINST THE GRAIN OF DEMOCRACY: the growing political awareness of school managers in Alagoas}

\begin{abstract}
1 Doutoranda em Educação. Universidade Federal de Alagoas - Brasil. Programa de Pósgraduação em Educação (PPGE/UFAL). Grupo de Pesquisa em Gestão e Avaliação Educacional. Orcid iD: https://orcid.org/0000-0002-1396-1543. E-mail: isabelamacena@yahoo.com

2 Doutoranda em Educação. Universidade Federal de Alagoas - Brasil. Programa de Pósgraduação em Educação (PPGE/UFAL). Grupo de Pesquisa em Gestão e Avaliação Educacional. Orcid iD: https://orcid.org/0000-0002-2423-4560. E-mail: eva.gomes@cedu.ufal.br

3 Doutora em Educação. Universidade Federal de Alagoas - Brasil. Programa de Pósgraduação em Educação (PPGE/UFAL). Grupo de Pesquisa em Gestão e Avaliação Educacional. Orcid iD: https://orcid.org/0000-0001-8226-2466. E-mail: wiledna@uol.com.br
\end{abstract}

Revista Exitus, Santarém/PA, Vol. 11, p. 01 - 23, e020151, 2021. 
This article presents a mapping of the ways of choosing the school manager in the municipal public school system in Alagoas while analyzing the perceptions of the education secretaries about the profile of the school manager, election and appointment of principals. The discussion is made in the light of theorists such as Romão and Padilha (2000), Bernardo and Borde (2016), Mendonça (2000), Aguiar (2011). Paro (2003) among others. The study was carried out by means of a quantitative research with the application of a questionnaire with the education secretaries and presidents of the Union of Education Workers in Alagoas (SINTEAL) in order to understand the ways of filling the position of school manager in the municipal education system. Alagoas. Data analysis was done based on Content Analysis (BARDIN, 2011). The results show that Alagoas has been taking a path contrary to what determines goal 19 of the National Education Plan - PNE (20142024) with regard to the use of more democratic ways of choosing the school manager, because when making the comparison with research held in 2013 on the ways of choosing the school manager it was found that after 7 (seven) years the political indication is still the predominant form of provision in the state's municipal network.

Keywords: Provision of the position of school manager. National Education Plan. Alagoas Municipalities.

\section{À CONTRE-COURANT DE LA DÉMOCRATIE: la prise de conscience politique croissante des directeurs d'école d'Alagoas}

\section{RESUMEN}

Este artículo presenta un mapeo de las formas de elección del director escolar en el sistema de escuelas públicas municipales de Alagoas y analiza las percepciones de los secretarios de educación sobre el perfil del director escolar, elección y nombramiento de directores. La discusión se realiza a la luz de teóricos como Romão y Padilha (2000), Bernardo y Borde (2016), Mendonça (2000), Aguiar (2011), Paro (2003) entre otros. El estudio se realizó mediante una investigación cuantitativa con la aplicación de un cuestionario con los secretarios de educación y presidentes del Sindicato de Trabajadores de la Educación de Alagoas (SINTEAL) con el fin de comprender las formas de cubrir el cargo de director escolar en el sistema educativo municipal. Alagoas. El análisis de los datos se realizó con base en el análisis de contenido (BARDIN, 2011). Los resultados muestran que Alagoas ha ido tomando un camino contrario a lo que determina la meta 19 del Plan Nacional de Educación - PNE (2014-2024) en cuanto al uso de formas más democráticas de elección del administrador escolar, porque al hacer la comparación con la investigación realizado en 2013 sobre las formas de elección del administrador escolar se encontró que después de 7 (siete) años la indicación política sigue siendo la forma predominante de prestación en la red municipal del estado.

Palabras clave: Mise à disposition du poste de directeur d'école. Plan national d'éducation. Municipalités d'Alagoas.

\section{INTRODUÇÃO}


A meta 19 do Plano Nacional de Educação - PNE (2014-2024), Lei nº 10.172, de 09 de janeiro de 2001, estabelece que os estados e municípios brasileiros devem assegurar condições para efetivação da gestão democrática da educação. Associada a isso, determina também que a nomeação do gestor escolar deve ser a partir de critérios técnicos de mérito e desempenho e da consulta pública à comunidade escolar nas escolas públicas do Brasil. Segundo o Observatório do PNE4 (2020), não há um indicador que permita acompanhar o desenvolvimento dessa meta, sendo uma das mais difíceis de ser monitorada. Tal afirmação revela a importância do estudo apresentado neste artigo, que buscou compreender como se dá a escolha do gestor escolar da rede municipal de ensino em Alagoas, por meio de consultas sistemáticas durante a participação dos secretários nas reuniões realizadas pela União Nacional dos Dirigentes Municipais de Educação, seção Alagoas (UNDIME-AL), e por meio de ligações telefônicas para os presidentes do sindicato dos Trabalhadores de Educação de Alagoas (SINTEAL).

Este artigo apresenta uma comparação com estudo realizado em 2013 sobre as formas de provimento ao cargo de gestor escolar em Alagoas (SANTOS e PRADO, 2014). Em 2013, eram 15\% de diretores eleitos e $78 \%$ de diretores indicados politicamente na rede pública municipal de ensino de Alagoas. Um dos objetivos deste artigo é analisar se houve avanços ou retrocessos nesses sete anos que separam um estudo do outro. Na rede estadual, desde 1999, foi implantada a gestão democrática e a forma de provimento do cargo de gestor por eleição, no entanto, de acordo com estudo de Silva e Santos (2017), mesmo na rede estadual de Alagoas com a gestão democrática implantada, há uma problemática que envolve a situação da presença da indicação de professores para o provimento do cargo de gestor escolar. As autoras advertem que a precariedade (estrutural, formação docente e técnica, etc.) presente na rede e a

${ }_{4}$ O Observatório do PNE (OPNE) disponibiliza indicadores de monitoramento das 20 metas e 254 estratégias do Plano, além de análises, um extenso acervo de estudos, vídeos e informações sobre políticas públicas educacionais. https://www.observatoriodopne.org.br/. Acesso em: 20 maio 2020. 
legislação estadual para a eleição de gestor têm contribuído para o aumento da indicação político-partidária na $6{ }^{a}$ Coordenadoria Regional de Educação, pertencente à Secretaria de Estado da Educação de Alagoas.

O processo de escolha do gestor escolar por indicação política vai na contramão do alcance da meta 19 do PNE (2014-2024), isso porque, um dos obstáculos para sua concretização é a influência político-partidária ainda presente em muitas escolas públicas do país, ou seja:

\begin{abstract}
A escolha e designação de dirigentes escolares predominantes no sistema escolar público brasileiro tem sido aquela decorrente do arbítrio do chefe do Poder Executivo, tanto no nível estadual quanto no municipal, por se tratar, em sua grande maioria, de cargos comissionados, comumente denominados cargos de confiança (ROMÃO e PADILHA, 2000, p. 93).
\end{abstract}

Para estimular o cumprimento da meta 19 pelos gestores municipais, o PNE (2014-2024) apresenta, como uma das estratégias, o repasse de verbas para aqueles estados e municípios que aprovem uma lei para garantir a escolha do gestor por meio de consulta à comunidade escolar e que levem também em consideração o mérito e desempenho do candidato. O texto do PNE (2014-2024) estabelece, nas Estratégias 19.1 e 19.2:

Priorizar o repasse de transferências voluntárias na área da educação para os Estados, o Distrito Federal e os Municípios que tenham aprovado lei específica prevendo a observância de critérios técnicos de mérito e desempenho e a processos que garantam a participação da comunidade escolar preliminares à nomeação comissionada de diretores escolares;

Aplicar prova nacional específica, a fim de subsidiar a definição de critérios objetivos para $\circ$ provimento dos cargos de diretores escolares.

Sendo assim, este artigo, por meio de dados quantitativos, visa a analisar quais as formas de escolha do gestor escolar estão sendo utilizadas em Alagoas. Para tanto, foi realizado um mapeamento sobre a forma de escolha do cargo de gestor escolar dos 102 municípios alagoanos e os secretários de educação foram indagados sobre a percepção que possuem a respeito da eleição de diretores. 
Quanto à estrutura, o presente artigo organiza-se em três seções, além desta introdução e das considerações finais. A primeira seção, intitulada "Gestão democrática e escolha do gestor no Brasil", tem a finalidade refletir sobre os avanços legais frente ao processo histórico da cultura política e democrática na educação brasileira. A segunda seção, "Formas de provimento ao cargo de gestor escolar em Alagoas: o que dizem os dados", apresenta a análise e a discussão sobre a problemática encontrada na contemporaneidade no estado de Alagoas com relação às formas de escolha do gestor escolar. A terceira seção, "A visão dos secretários municipais de educação sobre o perfil do gestor escolar, eleição de diretores e indicação política em Alagoas", traz o olhar dos dirigentes municipais sobre essas temáticas.

\section{GESTÃO DEMOCRÁTICA E ESCOLHA DO GESTOR ESCOLAR NO BRASIL}

Os estudos de Mendonça (2000), Paro (2003), Martins e Ferreira (2019), entre outros, mostram que o processo histórico da educação pública brasileira elucida um enfoque administrativo e organizacional centrado na figura do gestor. A partir disso, as relações de poder e os interesses individuais destacam-se sobre a conjuntura política, a qual abrange aspectos econômicos, sociais e culturais.

Desse modo, o tema gestão da educação tem sido discutido desde a década de 1980 no processo de redemocratização brasileira. A Constituição Federal de 1988, em seu Art. 206, destaca a "gestão democrática do ensino público, na forma da lei", visando ao desenvolvimento de uma cultura política e democrática, a qual busca, por meio de uma tarefa complexa assegurar a participação dos sujeitos envolvidos (BRASIL, 1988).

A partir da década de 1990, houve o fortalecimento das políticas públicas no contexto educacional e a Lei de Diretrizes e Bases da Educação Nacional - LDBEN, no 9.394/96, em seus artigos 14 e 15, apresenta as peculiaridades da gestão democrática, dando possibilidades para legitimar mudanças nas práticas administrativas, financeiras e pedagógicas (BRASIL, 1996). As mudanças constituem-se enquanto espaço de luta, pois "[...] 
administrar uma unidade escolar pública não é, de forma geral, uma tarefa fácil. Trata-se de um espaço de trabalho marcado e orientado por muitas contradições" (RIBEIRO e MONTEIRO, 2015, p. 364). Compreende-se que o desafio da sociedade civil está sob a legitimidade, a participação, a liderança e a qualificação, as quais fazem parte de uma estrutura organizacional para alcançar a autonomia pedagógica e administrativa. A partir desses desafios, destacam-se as formas de provimento do cargo do gestor escolar, as quais, segundo Mendonça (2000) e Paro (2003), podem ser representadas pelo concurso, seleção mista, eleição de diretor e indicação política.

O concurso público visa a impedir o apadrinhamento político, é realizado pela mediação da prova, qualificação profissional e nomeação dos primeiros colocados. Conforme Mendonça (2000, p. 191), "[...] está vinculado a uma concepção de direção de escola como carreira e, por meio dele, a ocupação da função tem caráter permanente". Desse modo, a comunidade escolar não participa do processo de escolha e o conhecimento do candidato sobre a praticidade do trabalho não é avaliado, pois não possui prova técnica.

Outra maneira de provimento do cargo de gestor é a seleção mista, a qual busca promover o processo seletivo e a eleição considerando a competência técnica, assim "[...] todos os sistemas que adotam esse procedimento baseiam-se na necessidade de superar os problemas de competência técnica dos candidatos" (MENDONÇA, 2000, p. 89). Esse tipo de seleção busca eliminar o favoritismo pela liderança política e permite a combinação de diferentes formas com o intuito de solicitar a participação da comunidade, bem como avaliar o conhecimento técnico.

A indicação política é caracterizada pela cultura tradicionalista, pois "[...] ainda que novas formas de ascensão ao cargo de diretor tenham estimulado processos de escolha democrática, é visível, porém, que estas convivem com práticas que ferem o princípio constitucional estabelecido há mais de 25 anos" (VIEIRA e VIDAL, 2015, p. 35), ocasionando, assim, o 
distanciamento da escola ao processo de construção do ambiente democrático.

Uma das aberturas para o alcance da democracia participativa no âmbito escolar é a eleição de diretor, a qual traz a possibilidade de escolha, sendo que o gestor "[...] tenderá com muito maior probabilidade a se comprometer com os interesses destes e a ganhar maior legitimidade nas reivindicações junto ao Estado" (PARO, 2010, p. 776). Dessa forma, não exercerá o papel do apadrinhamento político, mas, de acordo com Paro (2003, p. 100), essa opção de escolha não garante especificamente a participação dos sujeitos.

[...] uma importante característica das eleições é que, como todo processo de democracia, a participação e o envolvimento das pessoas como sujeitos na condução das ações é apenas uma possibilidade, não uma garantia. Especialmente em sociedades com fortes marcas tradicionalistas, sem uma cultura desenvolvida de participação social, é muito difícil conseguir-se que os indivíduos não deleguem a outros aquilo que faz parte de sua obrigação como sujeito partícipe da ação coletiva.

Paro (2003) afirma que a legislação traz a possibilidade de implementação da democracia, mas, de fato, as eleições não garantem a concretude das ações do trabalho coletivo, pois não há uma cultura de participação social instituída na comunidade escolar com o intuito de permitir o fim das práticas conservadoras, as quais se destacam pelos interesses e benefícios pessoais.

Ao perceber a legitimidade pela busca de ações democráticas no percurso histórico na sociedade brasileira e ao compreender a distinção de cada uma das especificidades sobre a escolha do gestor, a seguir, o olhar direciona-se para análise dos dados da presente pesquisa dando ênfase ao estado de Alagoas, representado por doze regiões administrativas e sendo constituído por 102 municípios, conforme gráfico a seguir. 
GRÁfICO 1 - Divisão Regional do Estado de Alagoas - Número de municípios
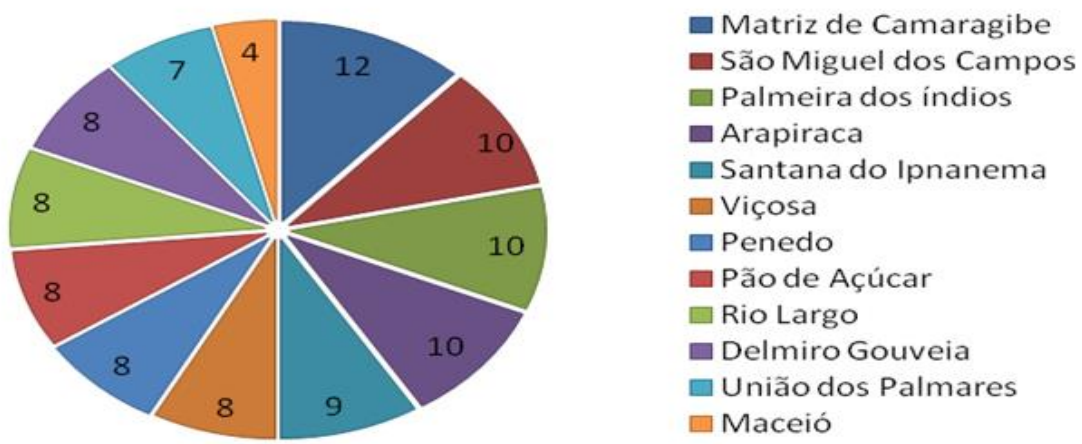

Fonte: Dados da pesquisa, 2019.

\section{O PROVIMENTO DO CARGO DE GESTOR ESCOLAR EM ALAGOAS: O que dizem os dados}

Após a aplicação dos questionários junto aos secretários de educação em reuniões da UNDIME-AL e ligações realizadas para os presidentes do SINTEAL, foi possível fazer o mapeamento das formas de escolha do gestor escolar em Alagoas. A figura, apresentada na sequência, ilustra como está a atual configuração do provimento desse importante e decisivo cargo para a busca da gestão democrática da escola pública alagoana:

FIGURA 1 - Formas de escolha ao cargo de gestor escolar em Alagoas - 2019 

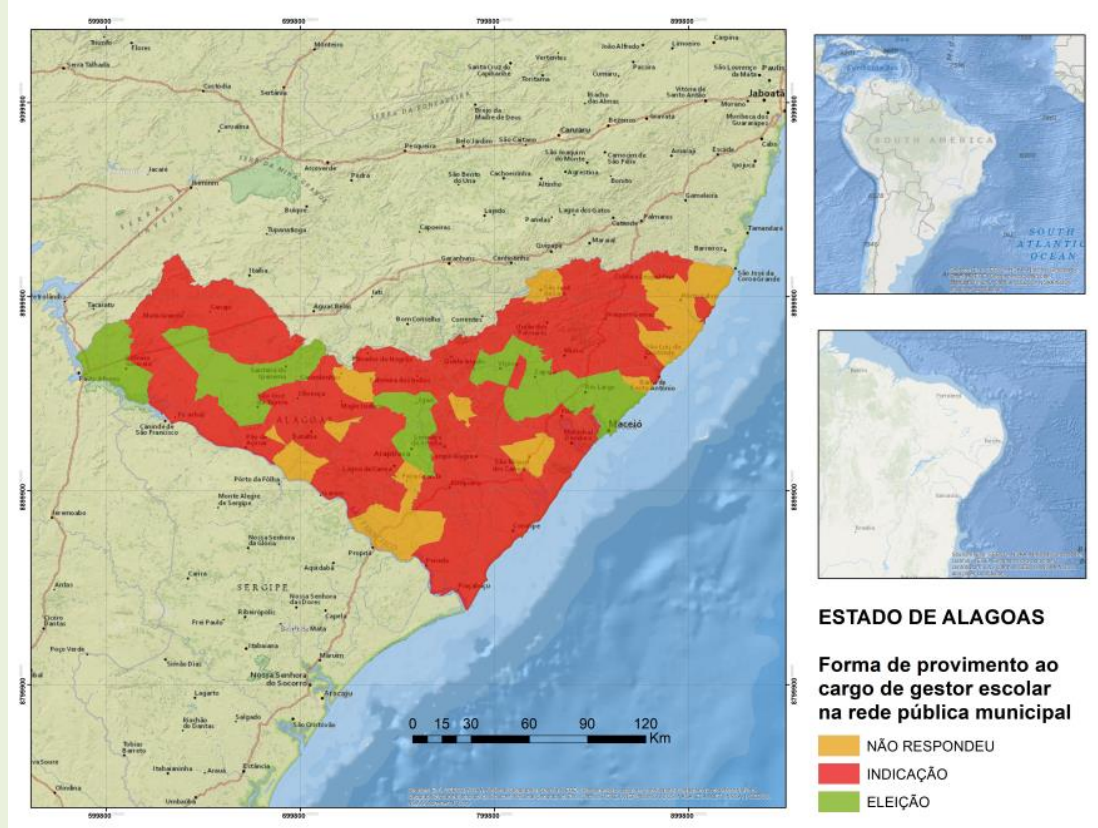

ESTADO DE ALAGOAS

Forma de provimento ao cargo de gestor escolar na rede pública municipal

NÃO RESPONDEU

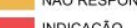

INDICAÇÃO
ELEIÇÃO

Fonte: Dados da pesquisa, 2019

Os municípios em vermelho representam as cidades alagoanas que escolhem o gestor por meio da indicação política, o que corresponde a $66 \%$ (67 municípios), ou seja, a maioria dos municípios da rede pública de Alagoas tem como forma de provimento ao cargo de gestor escolar a indicação político-partidária. Para Souza (2007, p.8), a indicação do gestor escolar "[...] representa uma intervenção direta do poder público nas escolas ou a utilização da direção escolar como peça do jogo políticopartidário cotidianamente executado nas políticas regionais e locais".

Fazendo uma comparação com pesquisa realizada sobre a forma de provimento ao cargo de gestor escolar na rede pública municipal de Alagoas, de acordo com Santos e Prado (2014), no período pesquisado, 78\% (80 municípios) alagoanos tinham, como forma de provimento do gestor escolar, a indicação político-partidária. Passados sete anos de realização da pesquisa, 66\% (67 municípios) alagoanos ainda têm, como predominância, a escolha do gestor escolar por indicação político-partidária. Como 20 secretários municipais não quiseram responder à pesquisa ou deixaram em branco a questão sobre a forma de provimento do cargo, o que corresponde a (19\%) do total de municípios, o número referente à forma de provimento por indicação pode ser ainda maior. Essa comparação revela que não houve grandes avanços no Estado com relação a uma forma 
considerada mais democrática de escolha do gestor escolar. Os dados também demonstram que, das 82 respostas coletadas, apenas 15 referem-se a municípios que apresentam eleição de diretores, o que corresponde a $15 \%$ do total de municípios alagoanos.

A indicação política ao cargo de gestor escolar é uma das formas de provimento mais criticadas pelos autores que estudam a temática (MENDONÇA, 2001; PARO, 2003; SOUZA, 2009; DOURADO, 2003). O poder político local tem a abertura para obter relações de troca de favores com a gestão da escola pública quando indica o gestor que assumirá $\circ$ cargo, muitas vezes, sem critérios específicos de desempenho, experiência ou formação desse gestor, isso porque "[...] na indicação do diretor, ocorre uma troca de favores que beneficia tanto o político profissional quanto o próprio gestor" (SILVA, 2013, p. 35).

O grande desafio posto aos governos locais encontra-se na própria meta 19 do PNE (2014-2024), que assegura criar condições para, no prazo de dois anos, haver a efetivação da "[...] gestão democrática da educação, associada a critérios técnicos de mérito e desempenho e à consulta pública à comunidade escolar, no âmbito das escolas públicas, prevendo recursos e apoio técnico da União para tanto (PNE, 2014-2024, grifo nosso). Isso porque a compreensão do que venha ser "consulta pública" é uma ideia muito genérica, podendo não deixar claro que essa consulta seria por meio de eleição direta com a comunidade escolar. Peroni e Flores (2014, p. 186) alertam para esse viés gerencialista e polissêmico da meta 19 quando afirmam que:

\begin{abstract}
Em nosso entendimento, esta redação tenta articular em um mesmo texto dois mecanismos de gestão que representam concepções diferentes e mesmo antagônicas de gestão, uma de matriz democrática e outra vinculada a modelos de viés gerencial, restando aos entes federados o desafio de implementar em conjunto critérios tão distintos. Cabe, ainda, destacar o fato de que a expressão "consulta pública" pode não significar exatamente a eleição direta de dirigentes escolares.
\end{abstract}

Sendo assim, o próprio PNE (2014-2024) não deixa claro como ocorrerá a consulta pública à comunidade escolar, podendo ocasionar 
entendimentos múltiplos. No entanto, o plano também não cita a indicação política como forma apropriada de provimento ao cargo de gestor escolar.

Em conformidade com Paro (2003, p. 26), a eleição de diretores é a forma de provimento que proporciona a participação da comunidade escolar, abrindo espaço para uma escolha democrática de quem irá gerir a escola, e tal mecanismo de escolha do gestor é importante porque "[...] à medida que a sociedade se democratiza, e como condição dessa democratização, é preciso que se democratizem as instituições que compõem a própria sociedade".

Nos dados apresentados no Quadro 1, verifica-se uma pequena predominância da cor verde relativa aos 15 (15\%) municípios alagoanos que adotaram, como forma de provimento do cargo de gestor escolar, a eleição de diretores. Observando, na sequência, todos os dados referentes a 2013 e 2019, é possível perceber uma similaridade no que tange ao total de 102 municípios alagoanos:

QUADRO 1 - Comparativo entre as formas de provimento do cargo de gestor escolar nas escolas públicas municipais alagoanas (2013/2019)

\begin{tabular}{|l|c|c|c|c|}
\hline \multirow{2}{*}{$\begin{array}{l}\text { Forma de } \\
\text { provimento }\end{array}$} & \multicolumn{2}{|c|}{2013} & \multicolumn{2}{c|}{2019} \\
\cline { 2 - 5 } & $\begin{array}{c}\text { Número } \\
\text { de } \\
\text { municípios }\end{array}$ & $\%$ & $\begin{array}{c}\text { Número } \\
\text { de } \\
\text { municípios }\end{array}$ & $\%$ \\
\hline Eleição direta & 15 & $15 \%$ & 15 & $15 \%$ \\
\hline $\begin{array}{l}\text { Indicação } \\
\text { política }\end{array}$ & 80 & $78 \%$ & 67 & $66 \%$ \\
\hline $\begin{array}{l}\text { Concurso } \\
\text { público }\end{array}$ & 1 & $1 \%$ & 0 & $0 \%$ \\
\hline Outros & 3 & $3 \%$ & 0 & $0 \%$ \\
\hline $\begin{array}{l}\text { Não } \\
\text { respondeu }\end{array}$ & 3 & $3 \%$ & 20 & $19 \%$ \\
\hline
\end{tabular}

Fonte: Dados da pesquisa de 2019 e de Santos e Prado (2014).

A consulta pública, importante instrumento de democracia, ainda não é realidade na maioria das escolas alagoanas, deixando abertura para a predominância do clientelismo e do apadrinhamento político na instituição escolar. Bastos (2001, p. 29) explica que, com a eleição de diretores, a comunidade escolar pode engajar-se para cobrar do diretor eleito a 
participação de todos nas decisões escolares, isso porque todos da escola "[...] conscientes da necessidade de um projeto democrático de educação podem constituir "núcleos de pressão" e exigir do diretor eleito o compromisso com a participação de todos na construção de uma escola democrática".

Na pesquisa de Silva e Santos (2018) sobre a rede estadual de educação em Alagoas, evidencia-se que, das 15 Coordenadorias Regionais de Educação do estado, apenas três não utilizaram a indicação políticopartidária como provimento da função de gestor escolar.

Os dados apresentados sobre a forma de provimento ao cargo de gestor escolar em Alagoas evidenciam a urgência de formas mais democráticas de escolha do gestor máximo das escolas no estado. Nos resultados, não foi destacado o concurso público como forma de provimento (em 2013, um município utilizava o concurso e, nos dias atuais, esse mesmo município adotou a indicação política como forma de provimento). Durante as duas pesquisas (2013 e 2019), não houve registro sobre a adoção da lista tríplice. Importante destacar que, como 20 municípios (19\%) consultados não responderam ao questionamento, pode haver outras formas de provimento que não foram identificadas e/ou um número ainda maior de indicações político-partidárias.

\section{A VISÃO DOS SECRETÁRIOS MUNICIPAIS DE EDUCAÇÃO SOBRE PERFIL DO GESTOR ESCOLAR, ELEIÇÃO E INDICAÇÃO DE DIRETORES EM ALAGOAS}

Na atualidade, a associação entre educação e qualidade tem se tornado um discurso recorrente. Se, por um lado, as concepções de educação e qualidade são construídas nas macropolíticas, numa perspectiva alinhada às lógicas internacionais, por outro lado, são nos micros espaços de cada escola que a gestão escolar procura articular estratégias para resolver os desafios constantes (PASCHOALINO, 2018, p. 1302).

Partindo do pressuposto de Paschoalino (2018), o discurso recorrente tem sido sobre a qualidade da educação e as instituições de ensino como instrumentos centrais para execução do trabalho desafiador concebido 
pela busca de práticas exitosas e de um ensino socialmente referenciado. Ribeiro e Monteiro (2018, p. 361) afirmam que algumas escolas "[...] em um determinado tempo, estão estruturalmente deterioradas - muitas vezes nas suas várias dimensões, humana, relacional e física - e em outro tempo estão bem organizadas, apresentando bons resultados". Desse modo, percebe-se a relevância da atuação do gestor escolar frente às suas diversas demandas.

Para a coleta dos dados, utilizou-se aplicação de questionários com os secretários municipais de educação de Alagoas. Com autorização da UNDIME-AL, aplicou-se o questionário com os secretários durante a realização de duas reuniões ordinárias realizadas na sede da associação na capital do estado. Na primeira reunião, foram entregues 60 questionários, 35 secretários fizeram a devolutiva. Tendo em vista o número de 102 municípios, foi necessária a aplicação em outra reunião, na qual muitos secretários presentes já haviam respondido anteriormente. No dia da pesquisa, foram entregues mais dez questionários e, desses, apenas quatro secretários responderam, totalizando 39 devolutivas. Dos 70 questionários entregues a secretários, 31 secretários recusaram-se a responder, não entregando a devolutiva ao final da reunião.

Diante do baixo retorno nas reuniões da UNDIME-AL, foram realizadas ligações telefônicas aos presidentes de todas as regionais do SINTEAL-AL, uma vez que eles têm conhecimento sobre todas as formas de gestão dos municípios coordenados por eles. Ao todo, foram realizadas ligações telefônicas para 12 seções regionais do SINTEAL. Entretanto, apenas as questões fechadas do questionário foram respondidas, em função da dificuldade que os diretores do sindicato apresentaram, alegando, como principal entrave, a falta de tempo no momento do contato.

Dessa forma, o gráfico, na sequência, diz respeito às respostas de 39 secretários, durante as reuniões da UNDIME-AL, acerca das características necessárias para a atuação como gestor escolar: 
GRÁFICO 2 - O que o gestor precisa saber para estar à frente de uma escola pública?

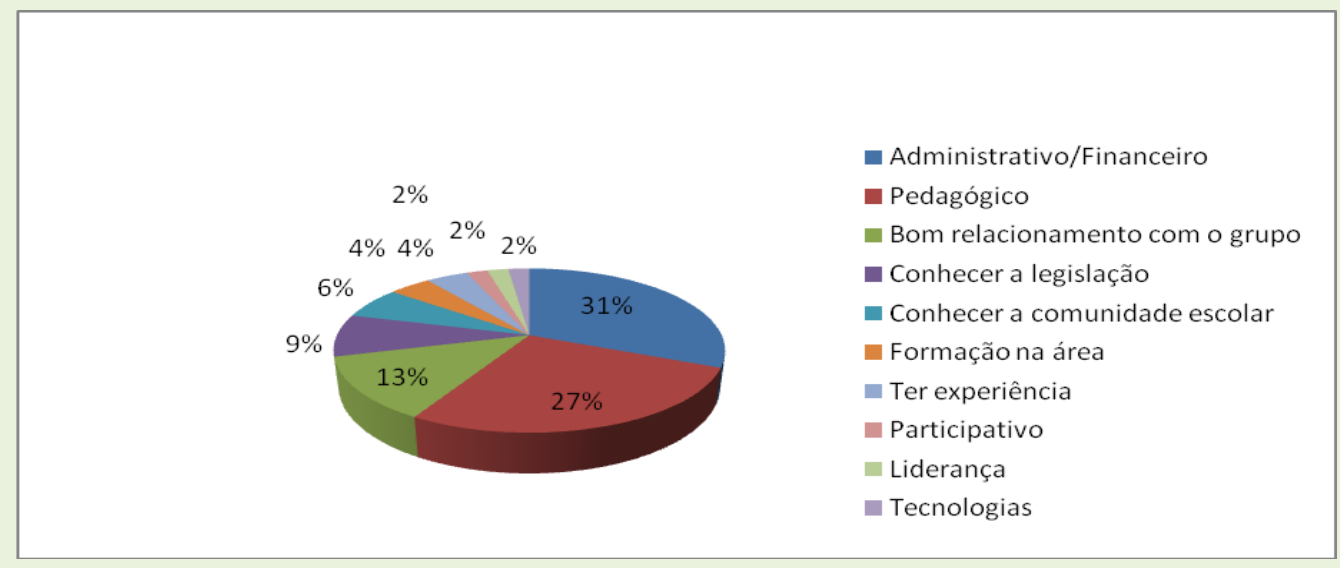

Fonte: Dados da pesquisa, 2019.

A partir do gráfico anterior, observa-se que há discrepâncias nos percentuais das respostas. Os dados mostram que $31 \%$ dos secretários de educação enfatizaram que o principal conhecimento que o gestor precisa ter é o Administrativo/Financeiro; enquanto $27 \%$ dão atenção ao conhecimento Pedagógico; $13 \%$ revelam que o bom relacionamento com o grupo torna-se fundamental para estar à frente de uma escola pública; 9\% afirmam que a centralidade está em conhecer a legislação; 6\% remetem à aproximação com a comunidade escolar; a formação na área e a experiência no cargo são destacadas apenas em 4\%; e os aspectos de liderança, participação e domínio das tecnologias são representados por $2 \%$.

Tendo em vista os conhecimentos mais destacados no gráfico, no que se refere aos procedimentos administrativo e financeiro, Gomes (2014, p. 42) afirma que ambos estão relacionados "[...] ao uso dos recursos recebidos e geridos no interior da escola, o que leva os responsáveis pela efetuação dos gastos a elaborarem prestação de contas de todo o financeiro despendido, através da apresentação de documentos comprobatórios". Há uma formalidade na exigência de alguns programas do governo federal, como, por exemplo, o Programa Dinheiro Direto na Escola (PDDE), que disponibiliza uma verba anual e, nos processos de compra, o gestor escolar é um dos 
líderes responsáveis para apresentar os documentos necessários, garantindo, assim, o distanciamento da improbidade administrativa. Neste sentido, os gestores capacitados nessa área conseguirão, segundo os sujeitos da pesquisa, alcançar resultados positivos.

O segundo caráter mais mencionado pelos secretários de educação é - conhecimento na área pedagógica, pois a gestão pode articular propostas e ações com os demais profissionais do âmbito escolar. Logo, "[...] está mais diretamente envolvida com o foco da escola que é o de promover a aprendizagem e a formação dos alunos" (LÜCK, 2009, p. 95).

Em terceiro lugar, na ordem de importância atribuída pelos respondentes, encontra-se o bom relacionamento com o grupo, característica que traz o foco na organização do trabalho, segundo Libâneo (2011, p. 338), "[...] a maneira pela qual se compreendem a divisão de tarefas e de responsabilidades e o relacionamento entre os vários setores determina a estrutura organizacional".

Nos questionários, os secretários municipais de educação também responderam com uma palavra ou frase a percepção que tinham sobre eleição de diretores e a indicação político-partidária, conforme mostram os dados a seguir.

\subsection{O que pensam os secretários de educação alagoanos sobre a eleição de diretores}

O quadro que segue apresenta a visão que os secretários de educação dos municípios alagoanos, sujeitos da pesquisa, têm acerca da eleição de diretores e sua importância para a gestão escolar. Para organizar os dados, as cores indicam aspectos que se aproximam mais de palavras e expressões ligadas a um campo semântico positivo ou mais a um campo semântico negativo, sendo que a análise foi feita com base na concepção de Freitas (2019, p.9) quando afirma que "por meio do campo semântico sabe-se/conhece-se o que outro é". Dessa forma organizou-se as falas e dividiu-se em frases positivas (boas, de apoio à eleição de diretores) e frases 
negativas (ruins, ou de desapoio à eleição de diretores). Os resultados são demonstrados no quadro:

QUADRO 2 - A percepção dos secretários entrevistados sobre a eleição de diretores

\section{ELEIÇÃO DE DIRETORES}

1-Participação da comunidade escolar

2-Democracia e cidadania

3-Apenas uma etapa da gestão democrática

4-Política Partidária

5-Necessário

6-Algo que o município não está preparado

7-Um problema, pois geralmente ganha o "mais querido" e não alguém que trabalhe em consonância e facilite as ações da secretaria

8-Importante para comunidade escolar

9-Importante

10-Justa

11-Importante

12-Importante para educação. É urgente.

13-Redemocratização

14-Não concordo plenamente. Temos vários exemplos negativos.

15-No nosso município ainda não é viável devido à política partidária

16-Parte do processo de gestão democrática

17-Democracia com responsabilidade

18-Excelente

19-Democracia

20-Importante, desde que não haja interesse político.

21-Democracia

22-Bom

23-A busca de uma gestão educacional mais democrática e coletiva

24-Ter compromisso com políticas educacionais. Valorização dos funcionários da educação.

25-Importante, porém somente isso não efetiva a gestão democrática

26-Significativa

27-É o que deveria acontecer para que assim a escolha fosse visando a experiência, sem apadrinhamento

28-Interessante, desde que haja maturidade dentro das escolas

29-Importante

30-Necessária para consolidação do processo democrático

31-Transparência

32-Autonomia de escolha

33-Democracia

34-Qualidade de ensino

35-Necessária

36-Uma conquista

37-Participação da comunidade

38-Fundamental

39-Importante

Legenda:

Revista Exitus, Santarém/PA, Vol. 11, p. 01 - 23, e020151, 2021. 
Aspectos negativos

Aspectos positivos

Fonte: Dados da pesquisa, 2019.

No que diz respeito às percepções positivas sobre a eleição de diretores, dos 39 secretários, 34, representados na cor salmão, identificaram palavras ou frases que reconhecem a importância da eleição de diretores. Cumpre destacar que, desse total, apenas seis secretários têm eleição de diretor em seus municípios. Tal dado demonstra que, mesmo nas cidades com indicação político-partidária, a eleição é considerada benéfica pelo gestor maior da pasta da educação.

Ainda nas falas em que a eleição é considerada positiva, houve algumas referências a cuidados que devem ser tomados para que a eleição realmente funcione. As observações feitas pelos secretários são referentes à necessidade de maturidade das escolas; real distanciamento da política partidária e compreensão de que a eleição de diretores sozinha não significa gestão democrática.

Referente às falas negativas, dos 39 secretários, cinco discordam de que a eleição de diretores seja eficiente. Tais secretários remeteram essa negatividade ao despreparo do município para realizar eleição, inclusive, por conta de a política partidária ainda ser muito forte na esfera local. Outro assunto apontado por eles é o descrédito na eleição de diretores, motivado por práticas negativas associadas à politicagem (aquilo que se critica nas eleições para cargos no legislativo e executivo acaba se reproduzindo nas eleições escolares, tais como a compra de votos em troca de favores). Como enfatiza Paro (2003, p. 29), ter eleição de diretores na escola "[...] não significa que o clientelismo tenha deixado de exercer suas influências na escola", sendo assim, eleição de diretores não é sinônimo de gestão democrática, sendo necessário, um conjunto de mecanismos para que ela aconteça.

Pelo exposto, mesmo que a maioria dos secretários de educação reconheça a importância da eleição de diretores, ela ainda é uma realidade muito distante de grande parte das escolas públicas alagoanas, 
uma vez que a indicação política está presente em $66 \%$ da rede pública municipal.

\subsection{O que pensam os secretários de educação alagoanos sobre a indicação político-partidária dos gestores escolares}

Os dados do Quadro 3 revelam a percepção dos secretários municipais de educação em relação à indicação político-partidária, forma de provimento ao cargo do gestor escolar que vem sendo destaque na sociedade alagoana, conforme já foi mostrado até aqui. Na organização dos dados, utilizaram-se os mesmos critérios do quadro anterior, identificação das cores salmão e verde, destacando as palavras ou frases que se aproximam de um campo semântico negativo ou positivo.

QUADRO 3 - A percepção dos secretários entrevistados sobre a indicação políticopartidária

\section{INDICAÇÃO POLÍIICO-PARTIDÁRIA}

\begin{tabular}{l}
\hline 1 - Profissionais com perfil administrativo \\
\hline 2 - \\
\hline 3 - Ato que exige análise e responsabilidade \\
4 - Longe da democracia \\
\hline 5 - Complicado \\
\hline 6 -Um problema. Grande parte deles são indicados por questão política \\
7 - Ideal para se trabalhar dentro de um planejamento. As coisas fluem mais, o diálogo é \\
mais produtivo e sem interesses de lado político. \\
\hline 8 - Precisa ser revisto \\
\hline 9 - \\
\hline 10 - Necessária \\
\hline 11 - Necessária na conjuntura atual \\
\hline 12 - Passado \\
\hline 13 - Clientelismo \\
\hline 14 - \\
\hline 15 - Necessária \\
\hline 16 - Possível, não deve ser atrelada a critérios mais técnicos \\
\hline 17 - Responsabilidade, confiança, construção coletiva \\
\hline 18 - Ruim \\
\hline 19 - Política \\
\hline 20 - É feita com o compromisso levando em conta a capacidade do diretor \\
\hline 21 - \\
\hline 22 - Seletivo \\
\hline 23 - A realidade da maioria dos municípios alagoanos \\
\hline 24 - \\
\hline 25 - É o meio que tem maior resultado até o momento \\
\hline
\end{tabular}




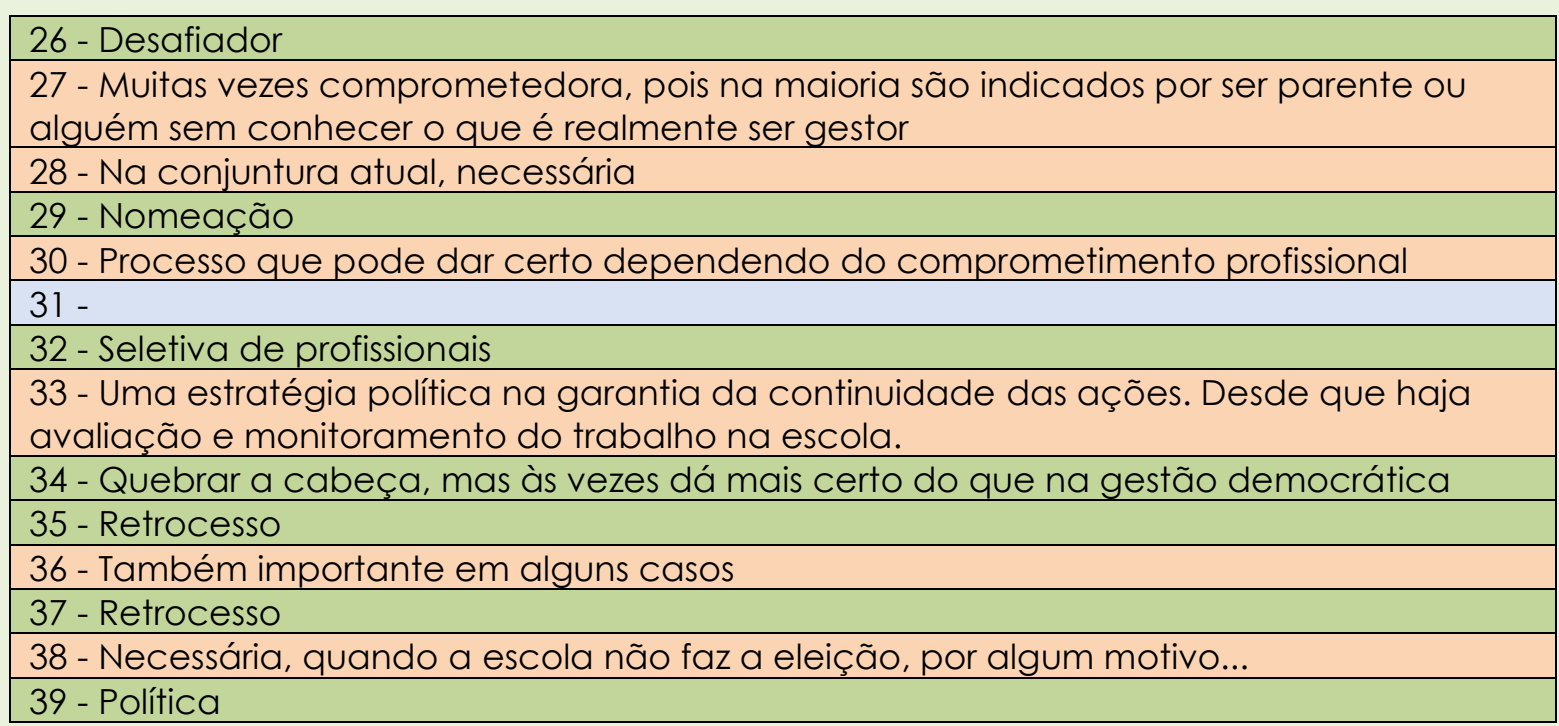

Legenda:

Aspectos negativos

Aspectos positivos

Não respondeu

Fonte: Dados da pesquisa, 2019.

Os dados organizados no quadro anterior constatam que, dos 39 secretários, 17, representados na cor salmão, mostram um olhar positivo e afirmam que a indicação político-partidária é necessária, além disso, realçam que essa forma de provimento ao cargo do gestor escolar busca a garantia de ações continuadas na instituição de ensino. Diante disso, destacam-se os termos "confiança, responsabilidade, construção coletiva", os quais são designados pelo apadrinhamento político, forte marca de uma sociedade clientelista e oligárquica, conforme mostra o estudo de Araújo (2007) sobre os desafios de uma gestão participativa em Alagoas.

Em relação aos aspectos negativos, 16 secretários, representados na cor verde, apresentam que a indicação político-partidária é problemática, pertencendo às práticas do passado, representante do clientelismo que ocasiona retrocessos no âmbito educacional e na contramão da democracia. Partindo desse pressuposto, nota-se que há um número significativo de percepções sobre o olhar negativo, pois, mesmo o município apresentando a forma de provimento do gestor escolar pela indicação política, os dirigentes municipais conseguem pontuar termos peculiares que 
registram o fracasso das ações conservadoras, oligárquicas e engessadas no estado de Alagoas.

Por fim, seis secretários, representados na cor azul, não responderam essa parte do questionário. Tal fato pode refletir a insegurança ou, até mesmo, medo de revelar a sua percepção frente à vivência de sua atuação do município pesquisado.

\section{CONSIDERAÇÕES FINAIS}

Buscou-se, no presente artigo, analisar comparativamente as formas de provimento ao cargo do gestor escolar na rede pública municipal no estado de Alagoas, nos anos de 2013 e 2019, com o intuito de perceber avanços e/ou retrocessos. Além disso, procurou-se identificar, dentro dessa temática, se os municípios estão seguindo os direcionamentos da legislação nacional. Em 2013, 80 municípios tinham gestores escolares no cargo oriundos de apadrinhamento político, 15 de eleição de diretores, um mediante concurso público, três por outras formas não declaradas e três casos em que não houve resposta. Sete anos depois, os dados de 2019 apontam que, dos 73 municípios que deram devolutiva aos questionamentos, 67 afirmam que o provimento ao cargo do gestor escolar dá-se pela indicação político-partidária, apenas 15 municípios identificaram que seus gestores são eleitos pela comunidade escolar e 20 não responderam.

A partir da análise realizada, percebe-se que os resultados obtidos são contrários à legislação abordada no texto, em especial, quanto ao que preconiza a meta 19 do atual PNE (2014/2024), pois ela afirma que os entes federados devem assegurar condições no prazo de dois anos para a efetivação da gestão democrática da educação, associada a critérios técnicos, bem como à consulta pública à comunidade escolar. Ao longo do texto, tornou-se possível perceber que, durante seis anos de vigência do Plano Nacional de Educação - PNE (2014/2024), pouco foi feito nas redes públicas municipais de Alagoas a fim de garantir o cumprimento da referida meta. 
Da CF/1988 (BRASIL, 1988), passando pela LDBEN 9.394/96 (BRASIL, 1996), até chegar ao PNE mais recente, a participação da comunidade escolar, com o intuito de consolidar práticas democráticas, torna-se eixo central a nortear as políticas públicas. Entretanto, a presente pesquisa constatou que, nos anos analisados 2013 e 2019 -, não houve avanço significativo nas práticas democráticas de escolha do gestor escolar. Os dados mostram que a velha política partidária prevalece, ao indicarem politicamente os gestores no âmbito escolar, na contramão da democracia. Desse modo, compreende-se que ainda é necessária e urgente "[...] uma consciência política mais desenvolvida e voltada para os interesses de todos na escola, sem restringir-se ao corporativismo estreito ou às imposições muitas vezes antieducativas do Estado" (PARO, 2003, p. 107).

A percepção dos secretários de educação frente às formas de provimento ao cargo do gestor escolar (eleição e indicação) foi relevante nesta pesquisa, pois o olhar da maioria dos secretários deu-se para o reconhecimento e a valorização da democracia, dando ênfase à eleição, no entanto, a indicação política ainda é a forma predominante de provimento do cargo de gestor escolar na rede pública municipal do Estado. Diante disso, pode-se indagar: há possibilidades de mudanças na educação em um cenário permeado por ações que inviabilizam o cumprimento dos preceitos legais na escola? Até quando a ausência de monitoramento das políticas públicas reforçará práticas conservadoras?

Por fim, espera-se que este trabalho tenha contribuído para suscitar novas reflexões entre os membros da sociedade alagoana e entre todos aqueles que lutam por uma educação pública socialmente referenciada, a partir da participação da comunidade escolar, foco e pressuposto do processo de mudanças.

\section{REFERÊNCIAS}

ARAÚJO, S. O. S. Gestão Democrática? Os desafios de uma gestão participativa na educação pública em uma sociedade clientelista e oligárquica. Maceió: EDUFAL, 2007. 
BASTOS, J. B. (Org.). Gestão democrática. 2. ed. Rio de Janeiro: DP\&A -SEPE, 2001.

BERNADO, E. S. PNE 2014-2024: Uma reflexão sobre a meta 19 e os desafios da gestão democrática. Revista Educação e Cultura Contemporânea, v. 13, n. 33, 2016.

BRASIL. Lei $\mathbf{n}^{\circ} \mathbf{9 . 3 9 4 / 9 6}$ de 20 de dezembro de 1996. Diretrizes e Bases da Educação Nacional. Brasília: Imprensa Oficial, 1996.

BRASIL. Constituição (1988). Constituição da República Federativa do Brasil. Disponível em:

<http://www.planalto.gov.br/ccivil_03/constituicao/constitui\%C3\%A7ao.htm> . Acesso em: 13 jan. 2018.

BRASIL. Lei Federal N. 13.005, de 25 de junho de 2014. Aprova o Plano Nacional de Educação. Brasília, 2014.

FREITAS, M. A. R. Campo Semântico: como reconquistar a linguagem primária da natureza humana. Saber humano, n.4, p.112-120, Ed. Especial, 2019.

GOMES, A. de C. C. Gestão Administrativa e Financeira na Escola Pública: um estudo de caso em escolas municipais de Rondônia no período de 20052013. Pós-Doutorado em Educação. UFPR, 2014.

LIBÂNEO, J. C.; OLIVEIRA, J. F. de; TOSCHI, M. S. Educação escolar: Políticas, Estrutura e Organização.10. ed. - São Paulo: Cortez, 2011.

LÜCK, H. Dimensões da gestão escolar e suas competências. Curitiba: Editora Positivo, 2009.

MARTINS, R. J.; FERREIRA, V. S. Meta 19 do Plano Nacional de Educação: gestão democrática gerencialista. Revista Textura, v. 21 n. 48 p. 202-219, out./dez. 2019.

MENDONÇA, E. F. A regra e o jogo: democracia e patrimonialismo na educação brasileira. 2000. 329 f. Tese (Doutorado) - Universidade Estadual de Campinas, Faculdade de Educação. Campinas/SP, 2000.

MENDONCA, E. F. Estado patrimonial e gestão democrática do ensino público no Brasil. Educação \& Sociedade. Campinas, vol. 22, n.75, 2001, p. 84108.

PARO, V. H. Eleição de Diretores: a escola pública experimenta a democracia. 2. Ed. São Paulo: Xamã, 2003. 
RIBEIRO, R.; MONTEIRO, S. Incubadora de gestores: rompendo o isolamento. In: DAVID, C. M. et al. (orgs.). Desafios contemporâneos da educação [online]. São Paulo: Editora UNESP; São Paulo: Cultura Acadêmica, 2015. Desafios contemporâneos collection, p. 359-370. ISBN 978-85- 7983-622-0.

SANTOS, I. M.; PRADO, E. C. Formas de provimento do cargo de gestor escolar em Alagoas: tendências e configurações atuais na rede de educação pública municipal. Cadernos do Tempo Presente, n. 16, mai./jul. 2014.

SILVA, L. A.; SANTOS, I. M. Limites e desafios da gestão democrática na escola pública: um estudo a partir do sertão alagoano. Revista Exitus, Santarém/PA, Vol. 8, No 1, p. 34-58, Jan./Abr. 2018.

SOUZA. A. R. Perfil da gestão da escola pública no Brasil: um estudo sobre os diretores escolares e sobre aspectos da gestão democrática. $30^{\circ}$. Reunião Anual da Anped. Caxambu. 2007. 17p. Disponível em: <http://www.anped.org.br/reunioes/30ra/trabalhos/GT05-3334-Int.pdf>. Acesso em: 20 mar. 2020.

SILVA, A. F. da. Poder político local e suas relações com a gestão da escola pública. Revista Exitus, Volume 03, Número 02, Jul./Dez. 2013.

VIEIRA, S. L.; VIDAL, E. M. Gestão Democrática da escola no Brasil: desafios à implementação de um novo modelo. Revista Iberoamericana de Educación, $n^{\circ} 67,2015$.

Recebido em: 20 de janeiro de 2021.

Aprovado em: 23 de abril de 2021.

Publicado em: 29 de abril de 2021 .

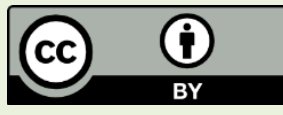

